\title{
Socioeconomic inequalities and the equity impact of population-level interventions for adolescent health: An overview of systematic reviews
}

\begin{abstract}
Objectives: Despite robust evidence on health inequalities in adulthood, less attention has been paid to inequalities in adolescence. The aim of this overview was to examine systematic review (SR) evidence on the equity impact of population-level interventions intended to improve health, happiness and wellbeing for adolescents.

Study Design: An overview (review of systematic reviews).

Methods: Eleven electronic databases were systematically searched to identify SRs of population-level interventions for adolescent health. A secondary data analysis of socioeconomic inequality was conducted to identify whether SRs reported on primary studies in terms of disadvantage, by measures of socioeconomic status (SES) and by differential effects.
\end{abstract}

Results: 35,310 review titles were screened; 566 full texts were retrieved and 140 SRs met the predefined selection criteria. Differential intervention effects were considered in 42/140 (30\%) SRs, 18/140 (13\%) reported primary studies using an SES measure and 16/140 (11\%) explicitly reported differential effects. $15 / 140$ SRs (11\%) explicitly focused on socioeconomic inequalities; of these $4 / 15$ reported differential intervention effects in more detail, $7 / 15$ concluded there was insufficient primary evidence to identify the impact of interventions on socioeconomic inequalities and 4/15 planned to examine differential effects by SES, but this was not reported further.

Conclusions: Our overview identifies that there is limited SR evidence on the equity impact of population-level interventions for adolescent health. Strengthening the evidence on whether interventions narrow or widen inequalities for adolescents must be a priority for public health research.

Accepted refereed manuscript of:

Macintyre A, Campbell P, McLean J, Maxwell M, Pollock A, Williams J, Woodhouse A, Biggs H \& Torrens C (2020) Socioeconomic inequalities and the equity impact of population-level interventions for adolescent health: An overview of systematic reviews. Public Health, 180, pp. 154-162.

DOI https://doi.org/10.1016/j.puhe.2019.11.008

(C) 2019, Elsevier. Licensed under the Creative Commons Attribution-NonCommercial-NoDerivatives 4.0 Internationall http://creativecommons.org/licenses/by-nc-nd/4.0/ 


\section{Introduction}

Adolescent health is a contemporary global policy and research priority ${ }^{1-3}$. The transition from adolescence to early adulthood is an important, and yet often overlooked period, with significant implications for physical and mental health across the life course ${ }^{1,4,5}$. Poor physical health in adolescence, such as being overweight or obese, and risk behaviours such as substance misuse ${ }^{5,6}$, are linked to increased risk of chronic disease in adulthood ${ }^{2,3}$. Mental health problems, often first evident in adolescence, can negatively impact later in life $^{2}$. There is also increasing evidence of socioeconomic inequalities in adolescent health ${ }^{7,8}$. Recent studies point to a socioeconomic gradient in adolescent self-reported health and health behaviour ${ }^{4}$, and wider determinants including income inequality, education and employment can impact on health in adolescence ${ }^{3,8,9}$.

Despite increasing recognition of inequalities in adolescence, there is little evidence on what works to address these inequalities ${ }^{10,11}$. Interventions can fail to tackle inequalities, there can be 'intervention generated inequalities' ${ }^{12,13}$, and/or under-provision for those most in need ${ }^{14}$. Differential intervention effects can be defined as "differences in intervention effect between groups of lower and higher socioeconomic status" ${ }^{12}$, p.1 of 4). The Commission on the Social Determinants of Health, and the World Health Organization Knowledge and Measurement Network, have underscored the need for improved evidence on whether and how interventions impact on inequalities and the social determinants of health ${ }^{15,16}$. This is pertinent to adolescent health but is currently underexplored ${ }^{9}$.

Systematic reviews (SRs) are important sources of synthesised evidence for guiding research ${ }^{17}$, practice and policy ${ }^{18}$, but have been criticised for a lack of emphasis on health equity ${ }^{19}$. Overviews are a relatively new methodology which bring together data from systematic reviews and can provide a 'bird's eye view' for policymakers and practitioners ${ }^{20}$. An important overview ${ }^{11}$ of interventions on the wider determinants of adult health identified a paucity of SR evidence on differential intervention effects ${ }^{11,21,22}$. Whilst some SRs in youth health focus on health inequalities ${ }^{23,24}$, to the best of our knowledge there is no overview of SRs which considers the equity impact of population-level interventions for adolescent health. We present our findings of a secondary data analysis from a recent overview ${ }^{25}$ to address this gap. The aim of this overview was to examine the SR evidence on the equity impact of population-level interventions designed to improve health, happiness and wellbeing for adolescents. 


\section{Methods}

We conducted a systematic review of systematic reviews (an overview) of population-level (i.e. universal) interventions for adolescent health across a range of outcomes ${ }^{25}$. Here, we present a brief summary of the methods employed in the original overview, primarily focussing on the secondary equity analysis. Further details of the original report, which was conducted in Scotland, are published in full elsewhere ${ }^{25}$.

\section{Identification of reviews for inclusion in the overview}

We systematically searched 11 electronic databases (Cochrane Database of Systematic Reviews; Health technology assessments (HTA); Campbell Collaboration; EPPI; Joanna Briggs Library (JBI) ; Database of Reviews of Effects (DARE) MEDLINE, EMBASE, CINAHL, PsycINFO and PubMed) for SRs. Date and language limitations were applied (i.e. SRs published in English between 01 January 2005 and 07 March 2016 were included). The search strategy is shown in Supplementary File 1.

\section{Selection criteria}

Selection criteria were predefined and documented in a protocol. Table 1 summarises the eligibility criteria. The focus was population-level (i.e. universal) interventions intended to promote adolescent health, and on evidence relevant to the Scottish/UK context (See Supplementary File 1 for details on how relevance was assessed).

[Insert Table 1 here]

\section{Study selection}

One reviewer (XX) executed the search strategy and screened titles for any obviously irrelevant studies or duplications. Two reviewers (XX and XX or XX) independently screened abstracts. A random sample of abstracts (10\%) was independently checked by a third reviewer $(X X)$. Abstracts assessed as irrelevant were excluded and full text papers for all other papers were retrieved. Two reviewers (XX and XX or XX) independently applied selection criteria to the full texts. Consensus meetings were used to discuss any disagreements with a third reviewer $(X X)$.

\section{Quality assessment}

Methodological quality was assessed by two independent reviewers $(X X, X X$ or $X X)$ using the ROBIS tool ${ }^{26}$. Disagreements were resolved through discussion and consensus 
meetings. SRs were judged as low, unclear or high risk of bias ${ }^{26}$. SRs assessed as high risk of bias were subsequently excluded.

\section{Data collection and management}

Data extraction was conducted in two stages using pre-piloted data extraction forms.

\section{Stage 1: Data extraction and mapping}

Stage one involved one review author $(X X)$ extracting key data relating to the review focus, aim, participants, interventions, comparisons, outcomes and a brief summary on whether SRs reported on socioeconomic inequalities or equity. This data was then cross-checked by a second review author $(\mathrm{XX})$.

Within systematic reviews it is helpful to have a pre-defined framework under which disparate literature can be organised and presented. The U.S. National Prevention Strategy ${ }^{27}$, was used to map the SR evidence across seven topics: violence and abuse free living; active living; healthy eating; mental health and wellbeing; tobacco free living; sexual and reproductive health; preventing drug abuse and excessive drinking; and two additional topics: obesity and general health. A series of team discussions were held to reach consensus on methods for grouping SRs into the relevant categories.

\section{Stage 2: Equity lens data extraction and coding}

Stage one identified the need for a more in-depth 'equity lens' analysis, which was subsequently undertaken in stage two. Recent work has extended the PRISMA guidelines to facilitate an 'equity lens' 19,28,29, 30 p.56, 31p.234. Whilst there is no universally agreed definition, an 'equity lens' involves the assessment of the differential impact of interventions according to "socially stratifying factors" 30 p.62, including gender, race, and religion ${ }^{30}$. In keeping with health inequalities research in the $\mathrm{UK}^{32}$, we focus here on socioeconomic status (SES) ${ }^{11,12}$.

The secondary equity analysis was pre-specified in a protocol (Supplementary File 2). Data was extracted for 6 domains (See Figure 1), including whether the review: described primary studies in terms of disadvantage; reported outcomes for disadvantaged groups; reported by measures of SES; considered differential intervention effects; was focused on socioeconomic inequality ${ }^{1}$; or drew conclusions regarding socioeconomic inequalities. All included reviews were coded for each domain using predefined codes

\footnotetext{
${ }^{1}$ SRs were considered focused on socioeconomic inequality if: i) inequality/equity was mentioned in the title or ii) the research questions or objectives mentioned socioeconomic inequality/equity.
} 
(YES/NO/UNCLEAR/NOT APPLICABLE) by one reviewer (XX), and cross-checked by a second reviewer $(X X)$ (Supplementary File 2). Where a review reported on at least one primary study per domain this was coded as 'YES'.

[Insert Figure 1 here]

Additional data was extracted for reviews identified as 'equity focused': topic area, number of included studies, number of primary studies reported at the level of the review that described participants according to a measure of SES (e.g. education, income, occupation, deprivation, poverty or another relevant SES measure). We also identified (through title/abstract screening) how many of the primary studies reporting SES measures were explicitly focused on adolescents or young people.

\section{Data synthesis}

Data from all included reviews were synthesised within the evidence tables and narrative, categorised according to the U.S. National Prevention Strategy categories.

\section{Results}

\section{Results of the search}

We identified 35,310 reviews, screened 566 full text papers of which 140 reviews (reported across 148 publications) met the selection criteria. Of the 140 reviews, 15 were identified as 'equity focused'. We present the findings of the secondary analysis in two sections below; firstly for the 140 SRs, and secondly for the subset of 15 SRs considered 'equity focused'. The results of the search are shown in Figure 2.

\section{[Insert Figure 2 here]}

The evidence included in the SRs involved primary studies with a variety of study designs including randomised controlled trials, quasi-experimental studies, controlled trials, observational studies, interrupted time series studies, and qualitative studies. The majority of reviews employed a narrative synthesis (79/140). Key characteristics of included reviews are shown in Supplementary File 3.

\section{Equity analysis mapped to U.S. National Prevention Strategy}

Table 2 provides a summary of the equity analysis for 140 SRs mapped across the 9 topic areas. The majority of reviews $(76 / 140)$ reported on at least one question related to 
inequality or disadvantage; 64/140 did not consider SES, inequality or disadvantage at all². Across topic areas, 58/140 reviews of population-level interventions reported primary studies of interventions delivered with participants considered disadvantaged, or from disadvantaged areas. Disadvantaged groups were variously described as "low socioeconomic", 33 p.30. "areas of social disadvantage", ${ }^{34}$ p. 29 , "children from low socio-economic backgrounds" ${ }^{35} p$. 792, "children from schools in disadvantaged areas" ${ }^{36}$ p.e1362 (Table 2). Twenty-four reviews reported on the outcomes specifically for these disadvantaged groups ${ }^{34,35,37-58}$.

Formal quantitative measures of SES were reported in 18/140 SRs (Table 2). When reported, these measures varied widely. For example, "percentage of students eligible for free or reduced price school meals", ${ }^{48}$ p.973, proportion "living below federal poverty level" ${ }^{59}$ p. 511 , measures of area deprivation ${ }^{45}$, educational level ${ }^{37}$, or other measures such as the Family Affluence Scale ${ }^{58}$. Differential intervention effects were considered in 42/140 reviews (Table 2 ). Of these, $16 / 140$ reviews explicitly reported differential intervention effects, with several reviews reporting that they were unable to analyse differential intervention effects due to a lack of data in primary evidence (e.g. ${ }^{34,40,42,45,46,52-54,57,60-68}$ ). The quality of reported differential effects was inconsistent, precluding firm conclusions about whether interventions addressed or increased inequalities (Table 2).

[Insert Table 2 here]

\section{Systematic reviews specifically focused on socioeconomic inequality}

Fifteen reviews reporting 1720 primary studies, were judged as explicitly focused on inequalities (identified in title or an objective). Table 3 summarises the key characteristics of the 'equity focused' SRs presenting data from individual studies as reported by reviews. Further detail is provided in Supplementary File 4.

One third of these reviews focused on tobacco free living $(5 / 15)^{31,58,69-71}$, four on general health ${ }^{54,72-74}$, two on active living ${ }^{45,75}$, two on obesity prevention ${ }^{34,52}$, one on mental health ${ }^{57}$ and one on violence and abuse free living ${ }^{76}$. Two reviews were 'empty' (i.e. they contained no primary studies) ${ }^{74,75}$; one review ${ }^{57}$ did not report the number of primary studies.

Reporting on disadvantage and by SES measures

Over half $(8 / 15)$ of the 'equity focused' SRs described participants as disadvantaged $34,45,52,54,57,58,71,73$ and $6 / 15$ reviews reported on the impact of interventions for disadvantaged

\footnotetext{
${ }^{2}$ In a small number of instances ( $n=6$ responses) the judgement was considered 'unclear' and treated as 'NO' in the analysis. In addition 3 SRs were 'empty' reviews (i.e. they contained no primary studies) and therefore the judgement was recorded as N/A and treated as 'NO' in the analysis.
} 
groups $^{34,45,52,54,57,58}$ (Table 3). There was little consistency in the reporting of SES measures across SRs; 3/15 reviews used the PROGRESS reporting guidelines to extract SES data 31,34,71 (Table 3/Supplementary File 4). Parental education, income and other measures of SES (e.g. free school meals) were the most frequently reported outcome measures. Six reviews did not report any specific participant SES measure $57,69,70,74-76$. Of the reviews that did, just over a third (74/211) of included primary studies were explicitly focused on adolescents or young people.

\section{Reporting differential intervention effects}

Whilst the majority (11/15) of the 'equity focused' SRs considered differential intervention effects, just less than half $(7 / 15)$ concluded that there was insufficient primary evidence to identify the impact of interventions on inequalities ${ }^{34,45,54,57,70,71,73}$. Four SRs planned to examine differential effects by SES, but this was not reported further ${ }^{69,74-76}$.

Four reviews reported on differential effects in more detail. One SR on youth smoking found 7 (of 38) studies showed positive impact on inequalities, 16 showed neutral effects, 12 negative impact, 4 mixed and 1 unclear $^{58}$. Taxation/increasing the price of cigarettes had the most evidence for positive equity impact; however overall there was a lack of primary evidence ${ }^{58}$. A second SR looked at tobacco control interventions across the general population (including young people) ${ }^{31}$. For interventions specifically for young people (smoking bans in schools, restrictions on sales to minors) and across studies focused on young people, there was a lack of reporting differential effects by SES measures. For adults price increases had the most robust evidence for addressing socioeconomic inequalities ${ }^{31}$. A third SR evaluating universal school-based interventions found that 4 studies (of 20 studies reporting differential impact) showed positive impact, 6 negative impact, and 10 neutral effects ${ }^{72}$. None of the 'education-only' interventions had any (positive) impact on inequalities, and interventions that reduced inequality typically involved environmental change $^{72}$. Finally a fourth SR, focused on parental support interventions in obesity prevention, identified one primary study which evaluated SES as a moderating variable but found no effects ${ }^{52}$.

[Insert Table 3 here]

\section{Discussion}

Our secondary analysis revealed a striking lack of consideration of equity in SR evidence on population-level interventions across the field of adolescent health. Whilst $41 \%$ of reviews described participants in primary studies as 'disadvantaged'; less than a third considered 
differential intervention impact; 13\% described participants using a measure of SES; $11 \%$ reported differential intervention effects; and $11 \%$ were explicitly focused on socioeconomic inequalities.

For 'equity focused' reviews, there was insufficient evidence to identify which interventions were effective for reducing inequalities. Some highly tentative evidence suggests that pricing/taxation may be effective for targeting inequalities in youth smoking ${ }^{58}$, and environmental change in schools may be more likely address inequalities compared to education based strategies ${ }^{72}$. These findings align with evidence which suggests that 'upstream' policy interventions may be more effective at tackling inequalities than those focused at an individual level ${ }^{12}$. However, the limited data available here suggests cautious interpretation.

A key implication is the need to attend to equity in the design of evaluations of populationlevel interventions for adolescents. Our overview highlights the lack of consistency in measuring SES among adolescents, which has long been recognised as a challenge ${ }^{77}$. Greater clarity is required on which SES measures can be routinely employed in public health evaluations with young people ${ }^{78}$. Furthermore, several reviews indicated the need for adequate sample sizes for subgroup analyses, which necessitates early consideration of equity in the planning and design of public health evaluations.

There is also an urgent need for consideration of equity in SR evidence ${ }^{79,80}$. The PRISMA-E guidelines are an important step towards this aim ${ }^{29}$. Previous analysis suggests policy makers feel existing research does not indicate which interventions are most effective in tackling health inequalities ${ }^{81,82}$, and that evidence is dominated by evaluations of behavioural interventions ${ }^{13,83,84}$. This is significant given the intractable nature of the health inequalities in adolescence and adulthood, particularly in the United Kingdom ${ }^{85,86}$. Our findings identify a crucial gap in the evidence required to inform policies which effectively tackle health inequalities in adolescence.

We applied a rigorous systematic review process which included independent application of eligibility criteria, quality assessment ${ }^{26}$. A further strength is that we only included SRs considered low or unclear risk of bias. We recognise that excluded lower quality SRs may also consider inequalities; however we have no reason to believe that excluded SRs would be more likely to do so to a degree that would alter our key findings. We acknowledge that primary studies may be of varied quality and our analysis may not capture attention to inequalities by primary studies ${ }^{87}$. This is consistent with methodological challenges for overviews, where it can be difficult to distinguish between whether a review undertook a particular analysis, or whether this is due to the quality of reporting ${ }^{87,88}$. We also recognise 
that searching to March 2016 does not capture recent reviews, and primary evidence focused on equity may take time to reach SR evidence. Despite these limitations, focusing at the level of SRs permitted a snapshot of the evidence, which can support research efficiency, avoid waste, and inform policy and practice ${ }^{87,88}$.

We recognise that focusing on SES neglects other characteristics ${ }^{30}$ and the analysis could be strengthened by consideration of the full range of factors in the PROGRESS-plus framework $^{18,26,30}$. U.S. research and policy may focus on race/ethnicity (rather than socioeconomic disadvantage) ${ }^{89}$, which has not been captured here. As the original overview excluded reviews of interventions for populations at higher risk (See Vojt et al 2018 for an overview focused on interventions for vulnerable groups $)^{90}$, we may underestimate consideration of disadvantage. However, tackling health inequalities requires a focus not just on the most disadvantaged, but consideration of the social gradient in health ${ }^{10,82}$. Furthermore, focusing on adolescents and young people aged 10 to 24 years means that some included SRs had wide age ranges. If a more restricted age range had been applied the consideration of inequalities may have been sparser. We also acknowledge that our criteria for SRs to be considered 'equity focused' did not consider possible synonyms of 'equity' and 'inequalities' (e.g. disadvantage / disparity); however we consider these to be the most relevant terms for the purposes of this overview, informed by the PRISMA-E guidelines ${ }^{29}$. Finally, we recognise the secondary 'equity lens' analysis was applied post-hoc, which may introduce bias ${ }^{29}$. Overviews are a comparatively recent methodological tool in evidence synthesis ${ }^{88}$ and there does not yet appear to be clear guidance on how to incorporate a focus on equity.

\section{Conclusions}

This overview and additional equity analysis is, to the best of our knowledge, the first overview of SR evidence on the equity impact of public health interventions to improve adolescent health and wellbeing. We demonstrate that this is significantly lacking and highlight that strengthening the evidence on whether population interventions narrow or widen inequalities for adolescents is a priority for public health research and practice.

Supplementary File 1: Search Strategy and Coding Relevance to UK/Scotland

Supplementary File 2: Protocol for Inequalities Data Extraction

Supplementary File 3: Evidence tables of included systematic reviews

Supplementary File 4: Evidence tables of equity focused systematic reviews 


\section{Acknowledgements}

The authors would like to thank the Expert Advisory Group and the Adolescent and Young

People Stakeholder Group for providing their input and constructive criticism to the work.

\section{References}

1. World Health Organization. Health for the World's Adolescents. A second chance in the second decade. Geneva: World Health Organization;2014.

2. Patton GC, Sawyer SM, Santelli JS, et al. Our future: a Lancet commission on adolescent health and wellbeing. Lancet. 2016;387(10036):2423-2478.

3. Sawyer SM, Afifi RA, Bearinger LH, et al. Adolescent Health 1 Adolescence: a foundation for future health. Lancet. 2012;379(9826):1630-1640.

4. World Health Organization. Growing up unequal: gender and socioeconomic differences in young people's health and wellbeing. Health Behaviour in School Aged Children (HBSC) Study: International Report from the 2013/2014 Survey. Copenhagen: World Health Organization;2016.

5. Hale DR, Viner RM. Policy responses to multiple risk behaviours in adolescents. Journal of Public Health. 2012;34:I11-I19.

6. Petrou S, Kupek, E. Epidemiological trends and risk factors for tobacco, alcohol and drug use among adolescents in Scotland, 2002-13. Journal of Public Health. 2018:pp. 1-9

7. Moor I, Richter M, Ravens-Sieberer U, Ottova-Jordan V, Elgar FJ, Pfortner TK. Trends in social inequalities in adolescent health complaints from 1994 to 2010 in Europe, North America and Israel: The HBSC study. European Journal of Public Health. 2015;25:57-60.

8. Elgar FJ, Pfortner TK, Moor I, De Clercq B, Stevens G, Currie C. Socioeconomic inequalities in adolescent health 2002-2010: a time-series analysis of 34 countries participating in the Health Behaviour in School-aged Children study. Lancet. 2015;385(9982):2088-2095.

9. Viner RM, Ozer EM, Denny S, et al. Adolescent Health 2 Adolescence and the social determinants of health. Lancet. 2012;379(9826):1641-1652.

10. Graham H, Kelly, M.P. Health inequalities: concepts, frameworks and policy. London: NHS Health Development Agency;2004.

11. Bambra C, Gibson M, Sowden A, Wright K, Whitehead M, Petticrew M. Tackling the wider social determinants of health and health inequalities: evidence from systematic reviews. Journal of Epidemiology and Community Health. 2010;64(4):284-291.

12. Lorenc T, Petticrew, M., Welch,V., Tugwell, P. What types of interventions generate inequalities? Evidence from systematic reviews. Journal of Epidemiology \& Community Health. 2012

13. McAuley A, Denny C, Taulbut M, et al. Informing Investment to Reduce Inequalities: A Modelling Approach. Plos One. 2016;11(8).

14. Tudor Hart J. The Inverse Care Law. The Lancet 1971;297(7696):405-412

15. Commission on the Social Determinants of Health. Closing the gap in a generation: health equity through action on the social determinants of health. Final Report of the Commission on Social Determinants of Health. Geneva World Health Organisation 2008.

16. Kelly MP, Morgan, A., Bonnefoy, J., Butt, J., Bergman, V. The social determinants of health: Developing an evidence base for political action. Final Report to World Health Organization Commission on the Social Determinants of Health World Health Organization 2007.

17. Chalmers I BM, Djulbegovic B, Garattini S, Grant J, Metin Gülmezoglu A, Howells DW, loannidis JPA, $\mathrm{S}$ O. How to increase value and reduce waste when research priorities are set. Lancet 2014;383:156-165. 
18. Waters E, Hall BJ, Armstrong R, Doyle J, Pettman TL, de Silva-Sanigorski A. Essential components of public health evidence reviews: capturing intervention complexity, implementation, economics and equity. Journal of Public Health. 2011;33(3):462-465.

19. Welch VA, Petticrew, M., O'Neill, J., Waters, E., Armstrong, R., Bhutta, Z.A., Francis, D., Koehlmoos, T.P., Kristjansson, E., Pantoja, T. \& Tugwell, P. . Health equity: evidence synthesis and knowledge translation methods. Systematic Reviews. 2013;2(43).

20. McKenzie JE, Brennan SE. Overviews of systematic reviews: great promise, greater challenge. Systematic Reviews. 2017;6.

21. Petticrew $M$, Tugwell $P$, Welch $V$, et al. Better evidence about wicked issues in tackling health inequities. Journal of Public Health. 2009;31(3):453-456.

22. Bambra C, Joyce KE, Bellis MA, et al. Reducing health inequalities in priority public health conditions: using rapid review to develop proposals for evidence-based policy. Journal of Public Health. 2010;32(4):496-505.

23. Oliver S, Kavanagh, J., Caird, J., Lorenc, T., Oliver, K., Harden, A., Thomas, J. Greaves, A. \& Oakley, A. . Health promotion, inequalities and young people's health. A systematic review of research. London: EPPI-Centre, Social Science Research Unit;2008.

24. Bambra CK, Hillier, F.C., Cairns, J.M., Kasim, A., Moore, H.J., Summerbell, C.D. . How effective are interventions at reducing socioeconomic inequalities in obiesty among children and adults? Two systematic reveiws Public Health Research 2015;3(1).

25. McLean J, Campbell P, Macintyre A, Williams J, Torrens C, Maxwell M, Biggs H, Pollock A, Woodhouse A. Health, happiness and wellbeing in the transition from adolescence to adulthood. A systematic overview of population level interventions. Edinburgh: Royal Society for Edinburgh 2017.

26. Whiting P, Savovic J, Higgins JPT, et al. ROBIS: A new tool to assess risk of bias in systematic reviews was developed. Journal of Clinical Epidemiology. 2016;69:225-234.

27. National Prevention Council. National Prevention Strategy. Washington, D.C.: Office of the Surgeon General;2011.

28. Maden M. Consideration of health inequalities in systematic reviews: a mapping review of guidance. Systematic Reviews. 2016;5.

29. Welch V, Petticrew M, Petkovic J, et al. Extending the PRISMA statement to equity-focused systematic reviews (PRISMA-E 2012): explanation and elaboration. Journal of Clinical Epidemiology. 2016;70:68-89.

30. O'Neill J, Tabish $\mathrm{H}$, Welch $\mathrm{V}$, et al. Applying an equity lens to interventions: using PROGRESS ensures consideration of socially stratifying factors to illuminate inequities in health. Journal of Clinical Epidemiology. 2014;67(1):56-64.

31. Thomas S. Population tobacco control interventions and their effects on social inequalities in smoking Tobacco Control. 2008;17:230-237.

32. Smith KE, Bambra, C. \& Hill, S. . Background and introduction: UK experiences of health inequalities In: Smith KE, Hill, S. \& Bambra, C., ed. Health inequalities. Critical perspectives. Oxford Oxford University Press 2016.

33. Walsh K, Zwi K, Woolfenden S, Shlonsky A. School-based education programmes for the prevention of child sexual abuse. Cochrane Database Syst Rev. 2015(4):CD004380.

34. Waters E, de Silva-Sanigorski A, Hall BJ, et al. Interventions for preventing obesity in children. Cochrane Database Syst Rev. 2011(12):CD001871.

35. van Cauwenberghe E, Maes L, Spittaels $\mathrm{H}$, et al. Effectiveness of school-based interventions in Europe to promote healthy nutrition in children and adolescents: systematic review of published and 'grey' literature British Journal of Nutrition. 2010;103(6):781-797.

36. Morgan PJ, Barnett LM, Cliff DP, et al. Fundamental movement skill interventions in youth: a systematic review and meta-analysis. Pediatrics. 2013;132(5):e1361-1383. 
37. Smedler A-CH, Anders;Wiklund, Stefan;Anttila, Sten; Pettersson, Agneta. Programs for prevention of externalizing problems in children: Limited evidence for effect beyond 6 months post intervention. Child \& Youth Care Forum. 2015;44(2):251-276.

38. Waddell C, Hua JM, Garland OM, Peters RD, McEwan K. Preventing mental disorders in children: a systematic review to inform policy-making. Can J Public Health. 2007;98(3):166173.

39. Carson KV, Brinn MP, Labiszewski NA, Esterman AJ, Chang AB, Smith BJ. Community interventions for preventing smoking in young people. Cochrane Database Syst Rev. 2011(7):CD001291.

40. MacArthur G, Harrison S, Caldwell D, M., Hickman M, Campbell R. Peer-led interventions to prevent tobacco, alcohol and/or drug use among young people aged 11-21 years: a systematic review and meta-analysis. Addiction. 2016;111(3):391-407.

41. Underhill K, Montgomery P, Operario D. Abstinence-plus programs for HIV infection prevention in high-income countries. Cochrane Database Syst Rev. 2008(1):CD007006.

42. Shepherd J, Kavanagh J, Picot J, et al. The effectiveness and cost-effectiveness of behavioural interventions for the prevention of sexually transmitted infections in young people aged 1319: a systematic review and economic evaluation. Health Technol Assess. 2010;14(7):1-206, iii-iv.

43. Blank L, Baxter SK, Payne N, Guillaume LR, Pilgrim H. Systematic review and narrative synthesis of the effectiveness of contraceptive service interventions for young people, delivered in educational settings. J Pediatr Adolesc Gynecol. 2010;23(6):341-351.

44. Blank L, Baxter SK, Payne N, Guillaume LR, Squires H. Systematic review and narrative synthesis of the effectiveness of contraceptive service interventions for young people, delivered in health care settings. Health Educ Res. 2012;27(6):1102-1119.

45. Baker PR, Francis DP, Soares J, Weightman AL, Foster C. Community wide interventions for increasing physical activity. Cochrane Database Syst Rev. 2015;1:CD008366.

46. Meester F, Lenthe FJ, Spittaels H, Lien N, Bourdeaudhuij I. Interventions for promoting physical activity among European teenagers: a systematic review International Journal of Behavioral Nutrition and Physical Activity. 2009;6:82(2).

47. van Sluijs EM, McMinn AM, Griffin SJ. Effectiveness of interventions to promote physical activity in children and adolescents: systematic review of controlled trials. BMJ. 2007;335(7622):703.

48. Driessen CE, Cameron AJ, Thornton LE, Lai SK, Barnett LM. Effect of changes to the school food environment on eating behaviours and/or body weight in children: a systematic review Obesity Reviews. 2014;15(12):968-982.

49. Long MW, Tobias DK, Cradock AL, Batchelder H, Gortmaker SL. Systematic review and metaanalysis of the impact of restaurant menu calorie labeling. Am J Public Health.

2015;105(5):e11-24.

50. Ganann R, Fitzpatrick-Lewis D, Ciliska D, et al. Enhancing nutritional environments through access to fruit and vegetables in schools and homes among children and youth: a systematic review BMC Research Notes. 2014;7(422):1-13.

51. Knai C, Pomerleau J, Lock K, McKee M. Getting children to eat more fruit and vegetables: a systematic review. Prev Med. 2006;42(2):85-95.

52. Kader M, Sundblom E, Elinder LS. Effectiveness of universal parental support interventions addressing children's dietary habits, physical activity and bodyweight: A systematic review. Prev Med. 2015;77:52-67.

53. Wang $\mathrm{Y}, \mathrm{Wu} \mathrm{Y}, \mathrm{Wilson} \mathrm{RF}$, et al. Childhood obesity prevention programs: comparative effectiveness review and meta-analysis Agency for Healthcare Research and Quality;2013.

54. Bonell C, Jamal F, Harden A, et al. Systematic review of the effects of schools and school environment interventions on health: evidence mapping and synthesis Public Health Res. 2013;1:1. 
55. Audrey S, Batista-Ferrer H. Healthy urban environments for children and young people: A systematic review of intervention studies. Health Place. 2015;36:97-117.

56. Hamm MP, Shulhan J, Williams G, Milne A, Scott SD, Hartling L. A systematic review of the use and effectiveness of social media in child health BMC Pediatrics. 2014;14:138.

57. Welsh J, Strazdins L, Ford L, et al. Promoting equity in the mental wellbeing of children and young people: a scoping review. Health Promot Int. 2015;30 Suppl 2:ii36-76.

58. Brown T, Platt S, Amos A. Equity impact of interventions and policies to reduce smoking in youth: systematic review. Tob Control. 2014;23(e2):e98-105.

59. Diep CS, Chen TA, Davies VF, Baranowsk JC, Baranowski T. Influence of behavioral theory on fruit and vegetable intervention effectiveness among children: a meta-analysis Journal of Nutrition Education and Behavior. 2014;46(6):506-546.

60. Morton KL, Atkin AJ, Corder K, Suhrcke M, van Sluijs EM. The school environment and adolescent physical activity and sedentary behaviour: a mixed-studies systematic review. Obes Rev. 2016;17(2):142-158.

61. Christensen H, Pallister E, Smale S, Hickie IB, Calear AL. Community-based prevention programs for anxiety and depression in youth: a systematic review. J Prim Prev. 2010;31(3):139-170.

62. Morton M, Montgomery P. Youth empowerment programs for improving self-efficacy and self-esteem of adolescents. Campbell Systematic Reviews. 2011.

63. Johnston $\mathrm{V}$, Liberato $\mathrm{S}$, Thomas $\mathrm{D}$. Incentives for preventing smoking in children and adolescents. Cochrane Database Syst Rev. 2012;10(10):CD008645.

64. Underhill K, Operario D, Montgomery P. Abstinence-only programs for HIV infection prevention in high-income countries. Cochrane Database Syst Rev. 2007(4):CD005421.

65. Lemstra M, Bennett N, Nannapaneni U, et al. A systematic review of school-based marijuana and alcohol prevention programs targeting adolescents aged 10-15 Addiction Research and Theory. 2010;18(1):84-96.

66. Kellou N, Sandalinas F, Copin N, Simon C. Prevention of unhealthy weight in children by promoting physical activity using a socio-ecological approach: what can we learn from intervention studies? . Diabetes and Metabolism. 2014;40:258-271.

67. Stice $\mathrm{E}$, Shaw $\mathrm{H}$, Marti CN. A meta-analytic review of obesity prevention programs for children and adolescents: the skinny on interventions that work. Psychological Bulletin. 2006;132(5):667-691.

68. Johnson BT, Scott-Sheldon LA, Huedo-Medina TB, Carey MP. Interventions to reduce sexual risk for human immunodeficiency virus in adolescents: a meta-analysis of trials, 1985-2008. Arch Pediatr Adolesc Med. 2011;165(1):77-84.

69. Patnode CD, O'Connor E, Whitlock EP, Perdue LA, Soh C, Hollis J. Primary care-relevant interventions for tobacco use prevention and cessation in children and adolescents: a systematic evidence review for the US Preventive Services Task Force Annals of Internal Medicine. 2013;158(4):253-260.

70. Moodie C, Stead M, Bauld L, et al. Plain tobacco packaging: a systematic review University of London, Institute of Education, Social Science Research Unit, EPPI-Centre; 30 March 2016 2012.

71. Rice N, Godfrey C, Slack R, Sowden A, Worthy G. A systematic review of the effects of price on the smoking behaviour of young people. Centre for Health Economics, the Centre for Reviews and Dissemination and the Department of Health Sciences (University of York) as part of the Public Health Research Consortium.;2009.

72. Moore GF, Littlecott HJ, Turley R, Waters E, Murphy S. Socioeconomic gradients in the effects of universal school-based health behaviour interventions: a systematic review of intervention studies. BMC Public Health. 2015;15(1):907. 
73. Hollands GJ, Shemilt I, Marteau TM, et al. Portion, package or tableware size for changing selection and consumption of food, alcohol and tobacco. Cochrane Database Syst Rev. 2015(9):CD011045.

74. Priest N, Armstrong R, Doyle J, Waters E. Policy interventions implemented through sporting organisations for promoting healthy behaviour change. Cochrane Database Syst Rev. 2008(3):CD004809.

75. Priest N, Armstrong R, Doyle J, Waters E. Interventions implemented through sporting organisations for increasing participation in sport. Cochrane Database Syst Rev. 2008(3):CD004812.

76. De La Rue L, Polanin J, Espelage D, Pigott T. School-Based Interventions to Reduce Dating and Sexual Violence: A Systematic Review. Campbell Systematic Reviews 2014;7.

77. Currie CE, Elton RA, Todd J, Platt S. Indicators of socioeconomic status for adolescents: the WHO Health Behaviour in School-aged Children Survey. Health Education Research. 1997;12(3):385-397.

78. Svedberg P, Nygren JM, Staland-Nyman C, Nyholm M. The validity of socioeconomic status measures among adolescents based on self-reported information about parents occupations, FAS and perceived SES; implication for health related quality of life studies. BMC Medical Research Methodology. 2016;16.

79. Tugwell $P$, Petticrew $M$, Kristjansson $E$, et al. Assessing equity in systematic reviews: realising the recommendations of the Commission on Social Determinants of Health. Bmj-British Medical Journal. 2010;341.

80. Priest $\mathrm{N}$, Waters $\mathrm{E}$, Valentine $\mathrm{N}$, et al. Engaging policy makers in action on socially determined health inequities: developing evidence-informed cameos. Evidence \& Policy: $A$ Journal of Research, Debate and Practice. 2009;5(1):53-70.

81. Petticrew M, Whitehead M, Macintyre SJ, Graham H, Egan M. Evidence for public health policy on inequalities: 1: The reality according to policymakers. Journal of Epidemiology and Community Health. 2004;58(10):811-816.

82. Davies JK, Sheriff, N.S. Assessing public health policy approaches to level-up the gradient in health inequalities: the Gradient Evaluation Framework. Public Health 2014;128:246-253.

83. Katikireddi SV, Higgins M, Smith KE, Williams G. Health inequalities: the need to move beyond bad behaviours. Journal of Epidemiology and Community Health. 2013;67(9):715716.

84. Craig N, Robinson, M. Towards a preventative approach to improving health and reducing health inequalities: a view from Scotland. Public Health. forthcoming

85. Royal College of Paediatrics and Child Health. State of Child Health Report London: Royal College of Paediatrics \& Child Health 2017

86. Burns H. Health inequalities - why so little progress? Public Health. 2015;129 849-853.

87. Baker PRA, Costello JT, Dobbins M, Waters EB. The benefits and challenges of conducting an overview of systematic reviews in public health: a focus on physical activity. Journal of Public Health. 2014;36(3):517-521.

88. Pollock A, Campbell P, Brunton G, Hunt H, Estcourt L. Selecting and implementing overview methods: implications from five exemplar overviews. Systematic Reviews. 2017;6(1).

89. Lynch JF, and Perera, I M. Framing Health Equity: US Health Disparities in Comparative Perspective. Journal of Health Politics Policy and Law. 2017;42(5).

90. Vojt, G., Skivington, K., Sweeting, H., Campbell, M., Fenton, C., \& Thomson, H. Lack of evidence on mental health and well-being impacts of individual-level interventions for vulnerable adolescents: systematic mapping review. Public Health, 161, 29-32. 